\title{
PENCEGAHAN PRAKTIK PROSTITUSI ONLINE MELALUI LEMBAGA SEKOLAH DAN KELUARGA
}

\author{
Diyah Utami, M. Jacky, Refti Handini Listyani \\ Fakultas Ilmu Sosial dan Hukum Universitas Negeri Surabaya \\ Email: reftihandini@unesa.ac.id
}

\begin{abstract}
Abstrak
Walaupun berbagai masalah timbul dari keberadaan prostitusi, kenyataannya penutupan prostitusi pun justru menimbulkan masalah baru. Penutupan prostitusi konvensial membuka peluang terciptanya prostitusi online, yakni prostitusi dengan memanfaatkan media sosial.Kelebihan prostitusi ini adalah lebih luas jangkauan geografisnya dan memudahkan menghindari pihak keamanan. Tulisan ini membahas tentang usaha pencegahan prostitusi online melalui lembaga keluarga dan sekolah. Kendala usaha pencegahan tersebut adalah terbatasnya pengetahuan para orangtua berkaitan dengan internet, apalagi terkait masalah prostitusi online. Keterbatasan pengetahuan tentang masalah internet tersebut tidak lepas dari latar belakang sosial orangtua yang berasal dari ekonomi bawah. Hal yang sama juga dengan sekolahsekolah daerah pinggiran, yang gurunya tidak banyak memiliki pengetahuan tentang internet dan keterbatasan dana untuk mengadakan acara-acara edukasi tentang bahaya internet. Salah satu jalan keluarnya adalah bantuan edukasi dari pemerintah dan juga lembaga-lembaga yang berfokus pada masalah anak dan remaja.
\end{abstract}

Kata Kunci : preventif, prostitusi, online, keluarga, sekolah

\begin{abstract}
Although various problems arise from the existence of prostitution, the fact that the closure of prostitution also raises new problems. Closure of conventional prostitution opens the possibility of creating online prostitution, ie prostitution by utilizing social media. The advantages of this prostitution are its wider geographic range and make it easier to avoid security. This paper discusses the prevention of online prostitution through family and school institutions. The problem is the limited knowledge of parents related to the internet, especially related to the issue of online prostitution. Limitations of knowledge about internet problems can not be separated from the social background of parents who come from the bottom economy. The same is true of suburban schools, whose teachers have little knowledge of the internet and the limited funds to organize educational events about internet dangers. One way out is educational support from the government as well as institutions that focus on the problems of children and adolescents.
\end{abstract}

Keywords:preventiton, prostitution, online, family, school

\section{Latar Belakang}

Walaupun selalu mendapat cibiran dan cemoohan, eksistensi prostitusi tidak lekang oleh waktu. Prostitusi terus bergeliat, beradaptasi menyesuaikan diri dengan perkembangan 
jaman. Beragam bentuk prostitusi, tak mengenal geografis ( desa maupun kota ), kelas atas (bertempat di hotel-hotel mewah ) sampai kelas bawah (pinggir jalan, warung remangremang, tempat lokalisasi ).Berbagai masalah pun muncul dari keberadaan prostitusi: meningkatnya penyebaran penyakit menular seksual, kekerasan yang dialami oleh para PSK, sampai dengan konflik dengan masyarakat sekitar. Hasil penelitian Phil Hubbard (2017, Agustus 1)yang berjudul Community Action And The Displacement Of Street Prostitution: Evidence From British Cities menjelaskan tentang gesekan antara penduduk asli dan para PSK. Penduduk asli menganggap prostitusi sebagai masalah sosial dan tidak diterima di sekitar tempat tinggal mereka. Hal ini menyebabkan pekerja seks perempuan termajinalkan dan belum ada penyelesaian masalah tersebut sampai sekarang.

Kebijakan penutupan lokalisasi di berbagai daerah juga tidak mampu sepenuhnya membunuh praktik bisnis yang dianggap kotor tersebut. Baru-baru ini pemerintah Kabupaten Tegal menutup tiga tempat lokalisasi di jalur pantura(Detik, 2017, Agustus 2). Tahun 2014, publik dihebohkan dengan rencana Walikota Risma untuk menutup prostitusi Dolly di Surabaya(BBC, 2017, Juli 3).Kurang lebih sepuluh tahun sebelumnya publik juga sempat dihebohkan dengan penutupan prostitusi Kramat Tunggak di Jakarta(Kompas, 2017, Juni 20)

Di era serba modern ini,penutupan lokalisasi tidak membuat para mucikari dan PSK kehilangan akal. Dengan memanfaatkan kecanggihan teknologi, beberapa mucikari dan PSK masih beroperasi menjual jasa pelayanan seksual. Teknologi yang dimaksudkan dalam hal ini adalah telepon seluler dan media sosial. Telepon seluler meningkatkan efisiensi dalam berkomunikasi. Sedangkan media sosial membantu orang-orang untuk berkomunikasi dalam jangkauan yang lebih luas ( tanpa batasan lokal, nasional maupun internasional ). Dua bentuk teknologi tersebut yang dimanfaatkan oleh para mucikari dan PSK dalam jaringan prostitusi online. Fenomena ini muncul pasca penutupan gang Dolly, sehingga memunculkan istilah baru yakni e-dolly (Modifikasi, 2016, September 3).

Prostitusi online memang menawarkan banyak kemudahan dibandingkan prostitusi konvensional. Sistem prostitusi online tidak jauh berbeda dengan sistem belanja online. PSK menawarkan diri melalui situs atau media sosial, calon pelanggan yang tertarik akan menghubungi PSK via internet, kemudian berlanjut dengan komunikasi via telepon genggam. Yang sering terjadi adalah calon pelanggan tidak langsung berhubungan dengan PSK yang diinginkan, tetapi melalui mucikari lebih dulu. Salah satu peran mucikari adalah memastikan bahwa calon pelanggan adalah orang yang serius ingin bertransaksi seksual, bukan sekedar main-main, apalagi aparat yang sedang menyamar. Beberapa kemudahan yang didapatkan dari sistem prostitusi online adalah pertama, memperluas jangkauan mucikari dan PSK untuk 
mencari calon pelanggan. Adanya media sosial membuat para mucikari dan PSK dapat melakukan 'mobilitas geografi virtual', tanpa harus berpindah-pindah lokasi. Media sosial yang sering dimanfaatkan sebagai sarana prostitusi adalah facebook dan twitter. Kedua, keuntungan yang didapatkan dengan memanfaatkan media online adalah mempersulit gerak aparat keamanan yang bertugas meringkus jaringan prostitusi. Bila merasa aksinya terendus aparat keamanan, jaringan prostitusi online tersebut akan segera meninggalkan akses akun facebook, twitter atau situs operasinya dan kemudian beralih membuat akun atau situs baru. Dalam dunia maya, berganti-ganti akun atau situs bukan sesuatu yang sulit.

Yang membuat miris adalah banyak dari PSK prostitusi online tersebut yang masih menyandang status pelajar(Sindo News, 2016, September 21). Hal ini tentu menimbulkan pertanyaan serius tentang sistem kontrol moral yang berlaku. Selama ini keluarga dan sekolah dikenal sebagai lembaga yang memiliki fungsi sosialisasi dan kontrol perilaku remaja agar tidak melakukan hal-hal yang menyimpang dalam masyarakat, termasuk prostitusi.

\section{Peran Lembaga Keluarga}

Sebagian besar masyarakat beranggapan bahwa keluarga memiliki banyak fungsi positif, misalnya pengaturan keturunan, sosialisasi atau pendidikan, ekonomi atau unit produksi, pelindung atau proteksi, penentuan status, pemeliharaan dan afeksi (Norma dan Sudarso, 2014: 214).Keluarga adalah miniatur mini masyarakat. Sebelum terjun ke tengahtengah masyarakat, anak lebih dulu 'ditempah' dalam lingkungan keluarga.

Tetapi, penggambaran di atas adalah adalah kondisi ideal sebuah keluarga. Tidak bisa dipungkiri apabila gambaran ideal tersebut jarang terjadi dalam masyarakat. Banyak kasus menunjukkan kegagalan keluarga menjalankan fungsi-fungsi di atas, sehingga memunculkan istilah anak atau remaja broken home. Prostitusi online yang melibatkan anak atau remaja bisa dikatakan adalah produk-produk broken home tersebut.Broken home bisa berwujud anak-anak atau remaja dari orangtua yang berkonflik atau terlalu sibuk bekerja, sehingga kurang mempedulikan kebutuhan dan perkembangan anak-anaknya. Tulisan ini tidak membahas tentang faktor-faktor penyebab anak atau remaja broken home, tetapi lebih menyoroti tentang peran lembaga keluarga dalam mencegah prostitusi online.

Penelitian yang dilakukan oleh Jacky Chau Khiu Cheung, Tak yan Lee, dan Jessica Chi mei Li(2017, Juni 15)yang berjudul Family centered Prevention of Adolescent Girls and Boys Prostitution menghasilkan beberapa saran bagi para orangtua untuk mencegah anakanak terjerumus ke dalam praktik prostitusi, antara lain yakni : menciptakan hubungan orangtua anak yang efektif ( penuh perhatian dan cinta ), meminta bantuan tenaga profesional 
pada saat mengalami krisis keluarga, pemberian pendidikan parenting serta dukungan dari pihak sekolah.

Penelitian di atas membahas pencegahan prostitusi secara umum. Dikarenakan pembahasan di jurnal ini lebih spesifik tentang prostitusi online, perlu diketahui lebih dahulu latar pemahaman keluarga Indonesia tentang praktik prostitusi online. Karena prostitusi online berkaitan dengan internet, maka penting untuk melihat karakteristik demografi pengguna internet di Indonesia. Menurut hasil riset nasional yang dilakukan Asosiasi Penyedia Jasa Internet Indones (APJII) dan Pusat Kajian Komunikasi Universitas Indonesia (UI), mayoritas pengguna internet di Indonesia berada dalam rentang usia 18-25 tahun. Jumlah golongan pengguna muda usia ini bahkan hampir setengah (49\%) dari total jumlah pengguna internet di Indonesia yang mencapai 88,1 juta di tahun 2014 kemarin(Liputan 6, 2016, Desember 20).

Internet memang memiliki magnet yang cukup kuat, terutama bagi anak dan remaja. Dikarenakan banyaknya hal menarik yang bisa diperoleh dari teknologi informasi tersebut, orang sering melupakan ataupun kurang paham tentang sisi negatif internet. Banyak kasus kejahatan yang memanfaatkan internet, mulai dari penipuan, pornografi sampai penculikan.

Di era globalisasi saat ini, memang tidak mungkin melarang anak untuk tidak 'bersentuhan' internet. Larangan tersebut justru akan membuat anak gagap teknologi dan tertinggal arus informasi. Yang harus dilakukan orangtua adalah membentengi anak-anak dari dampak negatif internet. Menurut para pakar psikologi, secara ideal, ada beberapa cara yang perlu dilakukan oleh orangtua untuk melindungi anak-anak dari bahaya internet :

1. Memberikan sosialisasi terhadap anak tentang dampak-dampak negatif internet

2. Membatasi jam waktu penggunaan internet

3. Mendampingi anak pada saat mengakses internet

4. Rajin mengecek situs, website atau layanan internet yang biasanya diakses anak

5. Memiliki pasword email, facebook, twitter atau jejaring sosial yang dimiliki anak

6. Memasang sofware kontrol pada piranti komputer

Kesimpulannya adalah untuk mencegah anak atau remaja terjerumus ke dunia prostitusi online, maka orangtua tidak hanya dituntut memberikan perhatian, kasih sayang dan dukungan, tetapi juga memiliki pengetahuan tentang dunia internet secara keseluruhan.

Bagi orangtua dengan basis pendidikan tinggi dan tingkat ekonomi menengah ke atas, tentu hal-hal di atas dapat mudah dilakukan. Tetapi, bagaimana dengan orangtua dengan tingkat status sosial ekonomi yang rendah ? Orangtua sering dianggap gagap teknologi. Bisa jadi banyak orangtua yang mengenal istilah internet, tetapi sedikit yang paham tentang fungsi 
dan penggunaannya. Apalagi bagi orangtua yang berasal dari kalangan ekonomi menengah ke bawah, internet tentu dianggap hal yang mewah. Sedangkan bagi anak dan remaja, teknologi baru adalah hal yang menarik, sehingga selalu ingin mempelajarinya. Maka tidak heran apabila internet tidak mengenal batasan latar belakang sosial di kalangan anak dan remaja. Untuk hal-hal yang berkaitan dengan internet saja banyak orangtua yang tidak paham, apalagi mengenai prostitusi yang memanfaatkan internet.Adanya gap atau kesenjangan pengetahuan orangtua dan anak tentang internet tentunya menyulitkan orangtua untuk mengontrol aktifitas internet anak-anaknya, termasuk ketika sang anak yang sudah beranjak dewasa terlibat prostitusi online. Rendahnya tingkat ekonomi orangtua, kurangnya kasih sayang dan minimnya kontrol orangtua terhadap aktifitas internet anak-anaknya, pada akhirnya menjerumuskan anak ke dalam praktek prostitusi online.

Selain itu, pemahaman secara normatif akan menyebutkan bahwa kurangnya pendidikan agama dalam keluarga adalah faktor penyebab munculnya perilaku prostitusi online. Tetapi, pencegahan secara spritual tentunya tidak cukup. Para orangtua perlu dibekali pengetahuan tentang internet, misal dampak-dampak negatif internet termasuk kejahatankejahatan online yang mengakibatkan anak atau remaja sebagai korbannya, atau pemberlakuan aturan akses internet bagi anak. Kekurangtahuan orangtua berkaitan dengan internet dapat diambilalih oleh pihak sekolah melalui program edukasi dan sosialisasi internet.

\section{Peran Lembaga Sekolah}

Lembaga sekolah sering dianggap sebagai 'rumah kedua' setelah keluarga. Sekolah adalah sarana sosialisasi anak tentang norma dan nilai yang berlaku dalam masyarakat. Selain itu, pengetahuan yang tidak diajarkan di dalam keluarga bisa didapatkan anak dari lembaga sekolah, termasuk yang berkaitan dengan internet.School acts as a bridge between the family and society as a whole, preparing children for their adult role(Haralambos and Holborn,2008: 779). Sama dengan fungsi keluarga sebelumnya, penggambaran tersebut adalah fungsi ideal sebuah sekolah. Lalu, bagaimana kondisi senyatanya.

Berkaitan dengan internet, kasus terungkapnya beberapa pelajar SMA yang terlibat prostitusi online tampaknya cukup menampar dunia pendidikan di Indonesia. Anggapan bahwa remaja SMA masih polos dan lugu tidak lagi tepat. Dalam usia yang masih belia, remaja berseragam abu-abu tersebut sudah terjebak dalam lingkaranprostitusi yang memanfaatkan teknologi. Hal ini tentu menimbulkan pertanyaan kritis tentang fungsi sekolah sebagai pranata ilmu. Sama halnya dengan kasus pranata keluarga, pendapat awam pun akan 
menganalisis tentang kurangnya pendidikan agama di sekolah sebagai faktor penyebab remaja menjadi bagian prostitusi online. Jarang ada yang berpikir tentang pentingnya bagi sekolah untuk memberikan program pendidikan internet bagi orangtua dan murid, sebagai salah satu bentuk pencegahan tindak prostitusi online. Hal ini perlu dilakukan, mengingat kekurangtahuan sebagian besar orangtua tentang dunia internet.

Secara ideal, ada beberapa langkah yang perlu dilakukan oleh pihak sekolah dalam rangka mengadakan program pendidikan internet :

1. Mengadakan sosialisasi tentang dampak-dampak internet pada remaja.

Wujudnya bisa berupa seminar parenting, sosialisasi di kelas (dalam atau luar jam pelajaran), atau sosialisasi pada saat pertemuan guru dan orangtua murid.

Bahan materi tentu bisa lebih luas, tidak hanya terkait prostitusi online saja, tetapi juga melihat aspek negatif internet dari sisi lain : cyber crime, pengaruh terhadap motivasi belajar atau kehidupan sosial remaja

2. Secara berkala dan acak, guru BK atau wali kelas mengontrol media atau jejaring sosial sosial yang biasa diakses oleh murid.

3. Pemberian banyak aktivitas pada murid untuk mengisi waktu luang di luar jam belajar, misal : ekstrakurikuler, outbond, camping dan masih banyak lagi lainnya. Tujuannya adalah agar murid tidak selalu menghabiskan waktu luangnya dengan berinternet.

Sayangnya, pelaksanaan program pendidikan internet tersebut tentunya membutuhkan sumber daya yang cukup, baik sumber daya manusia maupun finansial. Bagi sekolah dengan kualitas bagus, hal tersebut bukan sesuatu yang sulit.Seandainya tidak memiliki guru yang berkompeten untuk memberikan sosialisasi terkait pendidikan internet, sekolah dapat mengundang psikolog atau pakar pendidikan anak dan remaja.Tidak sulit juga bagi sekolah mengadakan acara atau aktivitas untuk mengisi waktu luang wali murid, dikarenakan kemampuan financiallatar belakang ekonomi wali murid yang tinggi

Tetapi, kondisinya tentu berbeda dengan sekolah-sekolah pinggiran. Latar belakang sosial ekonomi orangtua yang rendah membuat para siswi rawan terjerumus prostitusi online. Rendahnya tingkat finansial sekolah juga diikuti dengan rendahnya tingkat SDM tenaga pengajar, sehingga tidak memungkinkan memberikan sosialisasi atau pendidikan internet kepada siswa ataupun orangtua siswa. Pengertian pendidikan internet tidak hanya terkait operasionalisasi internet ( menggunakan media sosial dan penelusuran melalui searching engine ), tetapi juga meliputi masalah anak dan remaja yang berhubungan dengan internet. Pengadaan seminar parenting dengan mengundang psikologi atau pakar pendidikan 
anak tentunya juga membutuhkan biaya yang tidak sedikit, sehingga tidak memungkinkan sekolah untuk melakukannya.

\section{Kesimpulan}

Dengan melihat faktor keterbatasan keluarga dan sekolah-sekolah di Indonesia, rasanya tidak adil bila pencegahan prostitusi online hanya dibebankan pada pihak keluarga dan sekolah. Tidak kalah penting adalah peran negara dan lembaga swasta dalam hal pencegahan dan penanganan prostitusi online. Kepolisian, Kemenkominfo dan Kemendiknas adalah dua lembaga perpanjangan tangan negara, yang memiliki jalur tugas melakukan tindakan-tindakan preventif prostitusi online di kalangan remaja. Kepolisian dan Kemendiknas dapat bekerja sama melakukan sosialisasi ke sekolah-sekolah pinggiran terkait dampak-dampak negatif internet.Tidak kalah pentingnya adalah peran Lembaga Swadaya Masyarakat yang menaruh perhatian pada masalah-masalah perempuan, anak dan remaja, serta lembaga-lembaga perguruan tinggi.

\section{Referensi :}

\section{Buku}

Haralambos and Holborn, 2008. Sociology Themes and Perspective . Harper Collins Publisers Narwoko, Suyanto.(Eds).2004. Sosiologi Teks Pengantar dan Terapan. Jakarta : Prenada Kencana

Internet

$B B C$, 2017, Juli 3. "Dolly Jarak Tutup." Diakses dari http://www.bbc.com/indonesia/berita_indonesia/2014/06/140618_dolly_jaraktutu p).

Cheung, Jacky; Lee, Tak yan,dan Li, Jessica. 2017, Juni 15."Family Centered Prevention of Adolescent Girls Boy." Diakses dari www.familycouncil.gov.hk/.

Detik, 2017, Agustus 2. "Tiga Lokalisasi di Tegal ditutup, ratusan PSK dipulangkan." Diakses dari https://news.detik.com/berita-jawa-tengah/d-3506577/Tiga Lokalisasi di Tegal ditutup, ratusan PSK dipulangkan.

Hubbard, Phil. 2017, Agustus 1. "Community Action And The Displacement Of Street Prostitution: Evidence From British Cities." Diakses dari http://linkinghub.elsevier.com/retrieve/pii/S0016718598000141.

Kompas, 2017, Juni 20. "Andri Donnal Putera: Menengok Kembali Sejarah Penutupan Kramat Tunggak." Diakses dari http://megapolitan.kompas.com/read/2016/02/16/07000051/.

Liputan 6, 2016, Desember 20. "Adhi Maulana: Pengguna Internet didominasi Remaja dan Wanita." Diakses dari www. Liputan 6.com.

Modifikasi, 2016, September 3. "E-Dolly-Bisnis-Prostitusi-Lewat-Internet-Pengganti-GangDolly." Diakses dari http://www.modifikasi.com/showthread.php/568657-EDolly-Bisnis-Prostitusi-Lewat-Internet-Pengganti-Gang-Dolly). 
Sindo News, 2016, September 21. "Polisi Bongkar Prostitusi Online." Diakses dari https://daerah.sindonews.com/read/1147100/23/polisi-bongkar-prostitusi-onlinepelajar-dan-mahasiswi-di-kediri-1476413288. 